\title{
Guerra de discursos: um estudo comparado da cobertura jornalística do conflito árabe-israelense ${ }^{1}$
}

Elissa Griner Taublib

Pontifícia Universidade Católica do Rio de Janeiro - PUC-Rio

Departamento de Comunicação Social - Bacharelado em Jornalismo

\section{RESUMO}

O objetivo desta pesquisa é entender a atuação da mídia brasileira na cobertura do conflito árabe-israelense, a partir de uma leitura comparada com os principais veículos norte-americanos. Os jornais estudados foram Folha de S. Paulo, Estado de S. Paulo, The New York Times e The Washington Post. As coberturas foram analisadas a partir de elementos como: caráter informativo ou opinativo da reportagem, seleção de imagens nas matérias, composição das manchetes, fontes de informação e se há presença de contexto histórico e político. Este estudo buscou evidenciar a homogeneidade observada em reportagens brasileiras acerca do conflito, por conta do predomínio das agências de notícias. Além disso, destacar que fatos são omitidos nessa cobertura, quem tem voz na mídia e de que modo esse conflito suscita um apelo emocional no público brasileiro e internacional.

\section{PALAVRAS-CHAVE}

Jornalismo internacional; Folha de S. Paulo; Estado de S. Paulo; The New York Times; The Washington Post.

\section{Introdução}

Este artigo tem como objetivo analisar a cobertura jornalística dos principais meios de comunicação brasileiros e norte-americanos acerca da guerra. Definem-se como objeto de análise as matérias publicadas nos veículos Folha de S. Paulo, Estado de S. Paulo, The New York Times e The Washington Post acerca do conflito árabeisraelense e as principais pesquisas acadêmicas já publicadas a respeito desse tipo de cobertura.

\footnotetext{
${ }^{1}$ Artigo derivado de monografia de graduação em Jornalismo, orientada pelo professor Arthur Ituassu e apresentada em dezembro de 2019.
} 
Como metodologia de pesquisa, utilizou-se a análise de conteúdo. Este conteúdo se remete aos produtos midiáticos de meios de comunicação brasileiros e norteamericanos a respeito do conflito árabe-israelense. Ou seja, uma análise das principais matérias online veiculadas nos jornais de maior circulação do Brasil e Estados Unidos que abordam, sob diversos ângulos, eventos referentes ao conflito sócio-político no Oriente Médio. Também procura-se analisar o conteúdo de pesquisas acadêmicas realizadas no âmbito do tema geral e dos subtemas desse projeto de pesquisa, de modo a entender a perspectiva de estudiosos do campo sobre esses assuntos e como isso pode contribuir para o avanço da pesquisa.

A partir da análise de estudos acadêmicos e de reportagens referentes ao conflito entre Israel e Gaza em maio de 2019, foi possível obter diversos resultados no que se refere a cobertura brasileira do conflito, comparada a cobertura norte-americana. Este estudo buscou evidenciar, principalmente, que fatos são omitidos nessa cobertura, quem tem voz na mídia e de que modo esse conflito suscita um apelo emocional no público brasileiro e internacional.

Na primeira parte deste trabalho, revisaremos uma literatura sobre o conflito árabeisraelense e os diferentes discursos midiáticos empregados na cobertura deste confronto. Na segunda parte, apresentaremos a metodologia e discutiremos os resultados da pesquisa com base na análise de fatores como: caráter informativo ou opinativo da reportagem; seleção de imagens nas matérias; composição das manchetes; fontes de informação e se há presença de contexto histórico e político.

\section{Jornalismo e conflito árabe-israelense}

Nesta seção faremos uma breve revisão de literatura sobre as complexidades históricas e simbólicas do conflito árabe-israelense e os discursos utilizados na cobertura jornalística desse confronto no Oriente Médio (BICKERTON, 2018; KLAUSNER，2018; BRATIC, 2006; BUMLER，1995; MONTEFIORE，2011). Optou-se pelo enfoque em certos aspectos, como um panorama histórico do conflito na região e na cidade de Jerusalém, uma definição de quem são os árabes palestinos e os judeus israelenses e seus laços identitários com Israel e como é realizado esse noticiário de guerra em cada lado do conflito e na mídia internacional. 


\subsection{As complexidades históricas e simbólicas do conflito árabe-israelense}

O conflito árabe-israelense se refere ao confronto travado na região do Oriente Médio que, antes do estabelecimento do estado de Israel em 1948, era conhecida como Palestina, e administrada pela Inglaterra após o fim da Primeira Guerra Mundial. A partir de 1948, a disputa entre judeus e árabes palestinos pelo território passou a repercutir em países dentro e fora da região. Com o destaque que a guerra adquiriu na mídia, torna-se primordial entender o contexto histórico, religioso e político por trás do conflito.

Bickerton e Klausner (2018) ressaltam que a identificação com essa terra diz respeito a laços históricos e identitários dos judeus e árabes palestinos. Ressalta-se que as origens da tensão não são necessariamente religiosas, mas territoriais, de segurança, e de diferenças culturais. Contudo, o conflito envolve três grandes religiões, pelo fato de a região apresentar lugares sagrados para diferentes crenças: Judaísmo, Islamismo e Cristianismo. Há, ainda, um fator econômico e político: o Oriente Médio contém grande parte das reservas mundiais de petróleo, e isso torna os países dessa região ainda mais importantes na geopolítica internacional.

Vale destacar que, tanto no lado israelense como no lado árabe palestino, há subdivisões internas. Bickerton e Klausner (2018) concluem que podemos utilizar o termo árabe para designar aqueles que se comunicam em árabe e se identificam com a cultura e valores árabes. Hoje em dia, eles são grande parte da população de países como Egito, Iraque, Líbano, entre outros. Já os judeus também não se identificam como uma raça, nem como apenas uma religião, ou como uma nacionalidade. Nesse sentido, eles são um grupo cultural, religioso e étnico (BICKERTON e KLAUSNER, 2018).

Sebag (2011) ressalta o papel de destaque de Jerusalém na história do conflito árabeisraelense. Montefiore (2011) ressalta que o atual estado de tensão entre judeus e árabes na cidade pode permanecer desse modo por décadas, e afirma que a condição para a paz existir é a solução de dois estados para dois povos: Israel e Palestina. Entretanto, no parlamento israelense, os partidos religiosos e nacionalistas se fortalecem e influenciam os partidos que se posicionam a favor da paz. Enquanto isso, no lado palestino, há o Fatah, secular e que visa a conciliação no conflito, e o Hamas, grupo fundamentalista islã que prega a extinção de Israel, realiza ataques terroristas para ter sua causa reconhecida, e governa a faixa de Gaza. Nesse sentido, 
Montefiore (2011) destaca o desafio de conciliar essas diferenças para que ambos lados trabalhem juntos e caminhem na direção de um processo de paz.

\subsection{Os diferentes discursos midiáticos na cobertura do conflito árabe- israelense}

O conflito árabe-israelense é um dos mais complexos da região do Oriente Médio, e, dada a extensa cobertura midiática voltada ao assunto, é também um dos conflitos mais debatidos internacionalmente em diversas esferas. Diariamente, ataques terroristas, bombardeios, ataques de foguetes e diversas outras imagens chegam até nós por meio da mídia televisiva, online, impressa e redes sociais, influenciando a forma com que pensamos sobre o conflito e os atores envolvidos nele (BICKERTON e KLAUSNER, 2018). Ademais, o noticiário de guerra traz imagens que têm apelo ao público, como a devastação física ocasionada pela guerra. Por conseguinte, o conflito em Gaza tem uma cobertura jornalística extensa, mesmo sendo uma guerra pequena tanto em termos de duração como em relação ao conflito árabe-israelense em um sentido temporal (BLONDHEIM e SHIFMAN, 2009).

De acordo com Gadi Wolfsfeld, Paul Frosh e Maurice T. Awabdy (2008), a construção de narrativas nesse cenário pode variar entre um modo vitimista e um modo defensivo na reportagem. O primeiro é empregado quando o país do veículo em questão sofreu um ataque trágico que ocasionou na perda de vidas, enquanto o modo defensivo é utilizado quando foi o país o responsável pelo ataque que gerou perdas no país inimigo. No modo vitimista, há um notável apelo emocional na cobertura do evento, aumentando o apoio ao país do veículo no contexto de guerra. A reportagem ocupa posição de destaque na cobertura e as vítimas do conflito são humanizadas, por meio de fotos, idades e nomes. Já no modo defensivo, há uma maior racionalização dos fatos para lidar com as mortes de civis no país inimigo. A matéria, então, não apresenta grande destaque na cobertura noticiosa no geral, as vítimas se tornam estatísticas e o evento é analisado de modo mais racional e metódico, com fontes militares e uma linguagem mais técnica (WOLFSFELD, FROSH e AWABDY, 2008).

Blondheim e Shifman (2009) entendem que, na cobertura midiática de guerras e conflitos, há três "arenas de noticiário": o noticiário de cada lado do conflito e a mídia internacional. Tem-se que o noticiário nacional no país envolvido na guerra é visto como importante para o governo e oficiais do país, porque o controle dessa cobertura é capaz de mobilizar o público e impactar a estabilidade política do local. Já atingir a 
mídia do lado opositor no conflito é também um dos objetivos na guerra, para influenciar a moral nacional do inimigo (BLONDHEIM e SHIFMAN, 2009). No que concerne a cobertura midiática internacional, a terceira arena, o impacto que ela apresenta na opinião pública é significativo, embora mais difícil de ser controlada por governos e fontes oficiais. Ressalta-se também os tipos de discurso da mídia nessa cobertura jornalística de guerras: o discurso de poder, de vulnerabilidade e de desastre. O posicionamento de poder destaca o país como mais forte e preparado para ganhar o conflito militar, já no de vulnerabilidade, ele se mostra vulnerável a possíveis desastres e ameaças. Já o terceiro discurso, de desastre, coloca-se em destaque o sofrimento das vítimas e a destruição ocorrida no país devido ao conflito (BLONDHEIM e SHIFMAN, 2009).

Voltando-se ao conflito árabe-israelense, Blondheim e Shifman (2009) apontam para os discursos de cada arena midiática no cenário referente ao conflito na faixa de Gaza em 2008 e 2009. No caso do Hamas, grupo que domina Gaza, o discurso empregado na mídia local é o de ressaltar o poder da organização. Já no lado israelense, notase a presença de dois posicionamentos: para mobilizar o apoio do público no ataque a Gaza, empregava-se o discurso de poder, contudo, de modo a alertar os civis das consequências de guerras como essa, utilizava-se também o discurso de vulnerabilidade a ameaças (BLONDHEIM e SHIFMAN, 2009). Já no que tange ao posicionamento do Hamas e de Israel perante a mídia internacional, observa-se que Israel ressalta sua vulnerabilidade, enquanto fontes do Hamas se posicionavam com o discurso do poderio da organização no confronto. Já a cobertura jornalística internacional da faixa de Gaza focava no aspecto de desastre, com imagens que demonstravam o sofrimento humano no local (BLONDHEIM e SHIFMAN, 2009).

Ressalta-se que o discurso empregado na arena de cada lado ecoava o discurso político de quem está no poder. Porém, na arena que diz respeito ao outro lado do conflito, observa-se uma contestação do discurso em voga: a mídia israelense não leva a sério o posicionamento de poder do Hamas, e emprega o discurso de vulnerabilidade dos palestinos no sentido de fraqueza - e não como ameaçado por desastre (BLONDHEIM e SHIFMAN, 2009). Por outro lado, a mídia que defende Hamas não foca no poder de Israel, mas sim na vulnerabilidade do país inimigo, com imagens do país devastado por ataques terroristas, por exemplo.

Na mídia internacional, a terceira arena, por um lado, Israel quer que o mundo o enxergue como vulnerável - o que não obtêm grande êxito -, mas veículos 
internacionais o retratam como extremamente poderoso em contraste com civis indefesos (BLONDHEIM e SHIFMAN, 2009). Enquanto o Hamas promove o discurso do desastre - divulgando imagens de sofrimento humano ocasionado por ações de Israel - ao mesmo tempo em que quer ser visto como poderoso, ressaltando suas vitórias. Porém, o discurso de desastre é predominante, e a maior parte dos veículos não trata com seriedade o posicionamento de poder (BLONDHEIM e SHIFMAN, 2009).

\section{A cobertura jornalística do conflito árabe-israelense em uma perspectiva comparada}

Para os fins desse estudo comparado de coberturas midiáticas, foi realizada uma análise das matérias online sobre os confrontos entre Israel e Gaza em maio deste ano publicadas nos veículos brasileiros e norte-americanos de maior circulação. Desse modo, foi feito um recorte temporal da cobertura jornalística em torno das matérias sobre o conflito entre Israel e Gaza que se iniciou no dia 3 de maio de 2019, após dois soldados israelenses serem feridos por foguetes atirados da faixa de Gaza, durante os protestos que ocorriam na fronteira da região. Como resposta, as forças aéreas israelenses realizaram um ataque aéreo, que resultou na morte de dois palestinos. Em seguida, Gaza atirou centenas de foguetes em direção a Israel, que, por sua vez, respondeu com um bombardeio aéreo e de tanques em Gaza e fortaleceu sua presença na fronteira. No dia 6 de maio, foi realizado um cessar-fogo, facilitado por mediadores egípcios. Essa sequência de fatos ganhou grande atenção da mídia brasileira e internacional, e, com isso, tornou-se possível uma extensa análise dessa cobertura neste recorte específico.

Essa pesquisa analisa os jornais Folha de S. Paulo e Estado de S. Paulo, em uma leitura comparada com os veículos norte-americanos The Washington Post e The New York Times. No total, foram analisadas 15 reportagens desses meios de comunicação sobre este conflito em Gaza entre os dias 4 e 6 de maio de 2019. A busca por essas matérias foi realizada de forma manual, com base na procura de palavras-chave acerca do conflito no Google. No que diz respeito a escolha dos veículos para este estudo, tem-se que ela considerou sobretudo o alcance potencial de cada um. Segundo dados oficiais de dezembro de 2017 do Instituto Verificador de Circulação, a Folha e o Estadão apresentam, respectivamente, tiragens (somando impresso e digital) no valor de 285.334 e 203.272. Por serem dois veículos com um dos maiores índices de circulação no Brasil, eles podem ser considerados jornais de referência no 
país. Desse modo, a análise do conteúdo que eles publicam pode servir como parâmetro para entender a cobertura feita no país acerca deste conflito. A Folha, por exemplo, além de ter uma editoria que cobre assuntos internacionais, também tem uma versão só de notícias do Brasil na língua inglesa. Já o Estadão também apresenta uma editoria internacional que cobre diversos assuntos, além de uma colaboração com o The New York Times. Nessa colaboração, há uma parte do site do Estadão dedicada ao "NYT International Weekly", pelo qual o veículo norte-americano providencia conteúdos sobre notícias internacionais de diversos assuntos.

O estudo considerou reportagens do The New York Times e The Washington Post em uma análise comparada, para entender melhor a cobertura jornalística brasileira sobre esse assunto. A pesquisa de comunicação política comparada leva em consideração diferentes contextos na análise de um objeto, e é uma ferramenta que nos permite chegar a conclusões que abranjam diferentes contextos culturais e que apontem as semelhanças e diferenças entre os objetos de investigação nos sistemas em que se encontram. Foram selecionados esses dois veículos norte-americanos por alguns motivos. Primeiramente, o fato de contarem com uma editoria que cobre diversos assuntos internacionais com, inclusive, repórteres apurando e escrevendo diretamente das regiões de conflito. Além disso, o fato desse conteúdo repercutir não somente nos Estados Unidos, contexto em que estão inseridos, como também no resto do mundo. Segundo dados do World Association of Newspapers and News (WAN-IFRA) publicados no "World Press Trends 2016", o The New York Times está entre os 20 veículos com maior índice de circulação no mundo, e o terceiro dentro dos Estados Unidos. Já o The Washington Post é o sexto jornal com maior alcance potencial em seu país.

Os indicadores da análise de conteúdo são: o caráter informativo ou opinativo da reportagem, a escolha de imagens nas matérias, a composição da manchete, se o texto é original ou proveniente de agência de notícias, as fontes de informação utilizadas e a presença de contexto histórico e político. Também procura-se analisar o conteúdo de pesquisas acadêmicas realizadas no âmbito do tema geral e dos subtemas desse projeto de pesquisa, de modo a entender a perspectiva de estudiosos do campo sobre esses assuntos e como isso pode contribuir para o avanço da minha pesquisa. A seguir, discutiremos as principais semelhanças e diferenças entre as coberturas dos veículos brasileiros e norte-americanos, quem tem voz nessa cobertura do conflito em Gaza, dentre outros fatores que compõem a reportagem e influenciam a percepção do público acerca do confronto. 


\subsection{Semelhanças e diferenças na cobertura do conflito árabe-israelense}

A pesquisa das matérias online publicadas na Folha de S. Paulo, Estadão, The New York Times e The Washington Post revelou diversos pontos convergentes e divergentes na cobertura do conflito entre Gaza e Israel em maio de 2019. Essa análise levou em consideração aspectos como: as manchetes, a predominância do caráter informativo ou opinativo, os recortes de informações e a presença de contexto histórico e político nos textos publicados.

No que concerne os pontos convergentes, observa-se que a maior parte das matérias busca ser mais informativa e o enfoque da cobertura no geral muda no decorrer do conflito. No dia 4 de maio, o principal foco das reportagens é o bombardeio israelense na faixa de Gaza, em represália aos foguetes lançados pelos palestinos. Já no dia 5 de maio, os jornais ressaltam sobretudo o número de vítimas com o aumento da violência do conflito. Por fim, no dia 6 de maio, as manchetes giram em torno, principalmente, do cessar-fogo mediado pelos egípcios.

Ademais, nota-se, na maior parte das matérias, o esforço de contextualizar os fatos. Esse contexto não deixa de ser um recorte da realidade, contudo nota-se que ele prevalece em matérias que buscam ser mais objetivas. Por conseguinte, na tentativa de mostrar os dois lados, as matérias buscam evidenciar o que o governo de Israel e o os palestinos - na maior parte dos casos se referindo ao Hamas e Jihad Islâmica, que controlam Gaza - falam acerca do conflito. A análise mostra que, na maioria dos casos, cada lado conta uma versão diferente dos fatos, e os jornalistas deixam espaço para o leitor chegar as suas próprias conclusões, por assim dizer. Por outro lado, há diversos pontos divergentes - dentro da cobertura brasileira e com relação a cobertura norte-americana - no que condiz ao recorte dos fatos e a construção das reportagens, pontos estes que serão explorados neste capítulo de resultados.

No que se remete ao contexto dessas reportagens, nota-se a atenção conferida às políticas do primeiro-ministro israelense Binyamin Netanyahu, e sobretudo suas alianças internacionais com líderes como Donald Trump, Vladimir Putin e Jair Bolsonaro. Outra questão importante neste conflito específico, e que é discutida em muitas matérias, diz respeito aos fatores que pressionariam Israel a realizar um cessar-fogo. Dentre eles, as negociações para formar uma coalizão governamental depois da vitória de Netanyahu nas eleições, o concurso musical Eurovisão, que estava previsto para ser realizado em Tel Aviv ainda em maio, e as comemorações pela criação do Estado de Israel. 
Um fator fundamental presente na maior parte das matérias analisadas é o panorama das manifestações em Gaza, que fazem parte do conflito na região. Na matéria da Folha de S. Paulo publicada dia 4 de maio, por exemplo, afirma-se que os organizadores dessas manifestações e o Hamas asseguram que a Grande Marcha do Retorno é um movimento independente, mas que Israel, por outro lado, acusa Hamas de orquestrar essas manifestações. Assim como em outros casos explorados nessa análise, a reportagem não chega a nenhuma conclusão. Não há, por exemplo, um esforço investigativo da Folha de S. Paulo ou do Estadão em revelar se há ou não ligações entre Hamas e a Grande Marcha do Retorno. Desse modo, a cobertura do conflito é limitada na medida em que muitas matérias dos jornais apenas reproduzem as informações das agências de notícias e expõem os discursos de cada lado do conflito. Nesse sentido, não há uma única verdade simplesmente comprovada, mas sim uma guerra de discursos na mídia entre ambos lados do conflito.

Tem-se, ainda, que cada lado do conflito também apresenta suas complexidades, o que torna essa "guerra de discursos" ainda mais particular. Por um lado, temos a Autoridade Nacional Palestina (ANP), controlada pelo Fatah, e os grupos Hamas e Jihad Islâmica, que disputam a liderança de Gaza, mas que às vezes trabalham em conjunto - vale lembrar, também, que Hamas é rival de Fatah. Aqui cabe ressaltar que, desde a Batalha de Gaza em 2007, a maior parte da Faixa de Gaza está sob o controle do Hamas, islamista e de orientação sunita, e não da Autoridade Nacional Palestina. Também é possível destacar que as reportagens se referem ao Hamas e a Jihad como grupos militantes islamistas, e Israel, Estados Unidos e União Europeia os consideram grupos terroristas, que pregam a destruição de Israel.

No outro lado, temos Israel, com um governo democraticamente estabelecido e um parlamento com grande diversidade política e políticos que, inclusive em matérias analisadas, criticam e contestam publicamente diversos passos tomados pelo Primeiro-Ministro. É importante entender as diferenças internas de cada lado do conflito e a forma com que são descritos nas reportagens, a fim de compreender como é realizada a cobertura deste cenário.

Um caso específico que se fez muito presente em matérias nacionais e internacionais referentes ao conflito condiz a polêmica em torno de duas vítimas: uma mulher grávida e um bebê, ambos palestinos. Na matéria da Folha de S. Paulo, consta que, segundo o Ministério da Saúde Palestino, os ataques israelenses causaram a morte de 19 palestinos, dentre eles essas duas vítimas. Já na cobertura do conflito realizada 
pelo Estadão, a reportagem deixa evidente que Israel afirmou publicamente que a morte da mulher grávida e do bebê que estava com ela foi causada, acidentalmente, por um foguete disparado pelo próprio Hamas, versão esta que é contestada pelos palestinos.

Desse modo, tem-se que, na matéria da Folha, há a omissão do posicionamento de Israel com relação a essas duas vítimas. Independentemente de qual seja a versão correta dos fatos, a omissão desse posicionamento é muito perigosa quando consideramos que a Folha é uma das principais fontes de informação dos brasileiros acerca do que ocorre no Oriente Médio. Como afirmado anteriormente, em um conflito como este, embora prevaleça a guerra de discursos na mídia, é necessário que ambos lados tenham voz para contar as suas versões dos fatos, e que os jornalistas apurem o máximo para chegar o mais perto possível da verdade, ou as diversas versões existentes da verdade.

No que se refere a análise das manchetes dos jornais brasileiros Folha e Estadão, tem-se que todas são marcadas pela presença de verbos - como "bombardeia", "matam", "causa" - o que Ihes confere um caráter mais informativo. O que poderia mudar era o enfoque da manchete: dependendo da ordem e da escolha das palavras, o enfoque poderia ser mais no ataque de Israel ou na represália de Israel após os ataques palestinos, o que também dependeria da dimensão conferida a cada lado. Mas, no geral, pode-se dizer que predominou o caráter objetivo e informativo na maior parte dos títulos das reportagens. Vale ressaltar que a maior parte das matérias da Folha foram traduzidas de textos de agências de notícias, e uma das reportagens do Estadão analisadas foi traduzida de uma reportagem do The New York Times, o que demonstra o alinhamento da cobertura desses dois jornais.

Sobre a cobertura realizada pelo The New York Times e The Washington Post, notase a maior diversidade de fontes, analistas, personagens e repórteres escrevendo e apurando na região. Todos esses aspectos enriquecem as reportagens e proporcionam diferentes enquadramentos para os fatos reportados, ao invés de meramente reproduzir conteúdo de agências de notícias. Observa-se que a maior parte das matérias pesquisadas são de cunho mais informativo, contudo, em matérias do The New York Times, nota-se uma escolha de palavras mais subjetiva, como no trecho publicado no dia 5 de maio: "a violent but localized expression of Palestinian impatience with Israel's failure to alleviate dire humanitarian conditions 
in Gaza." Outro exemplo é quando o jornalista do veículo descreve o cessar-fogo como "fragile" e "tentative".

\section{After Intense Fighting in Gaza, Israel and Palestinians Observe Ceasefire}

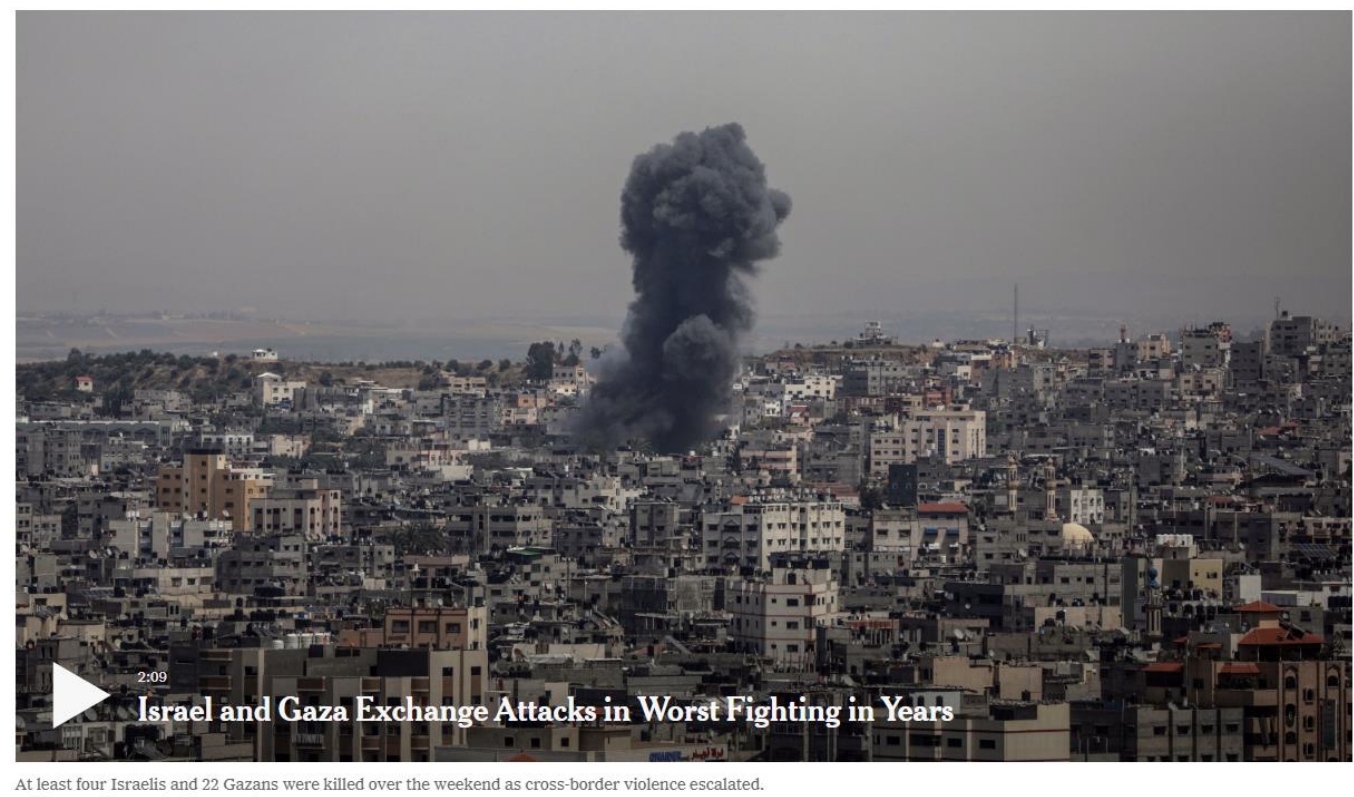

At least four Israelis and 22 Gazans were killed over the weekend as cross-border violence escalated.

Figura 1: Manchete de matéria publicada no The New York Times, 05/05/2019 (Fonte: The New York Times)

Uma das reportagens desse jornal caracterizada por esse teor analítico tem como manchete: Why do Israel and Gaza Keep Fighting? Because It's in Their Leaders' Interests. Apesar do caráter opinativo, a matéria é baseada em fatos reais do conflito, e traz análises, portanto, com embasamento e contexto histórico. Nesta matéria, o jornalista se baseia no discurso de especialistas sobre o conflito, e aponta que o ciclo de violência na região estaria, na realidade, servindo aos interesses de Israel e Hamas. Segundo a reportagem, por um lado, o governo de Netanyahu se utilizaria do conflito para embasar o seu discurso de que os palestinos não estariam prontos para a paz e que, portanto, a solução de dois estados para dois povos seria inviável. No outro lado, Hamas evidenciaria aos moradores de Gaza que a estratégia de resistência armada estaria funcionando. Esse tipo de reportagem, assim como outras mais analíticas desse veículo, buscou mostrar como esse conflito específico se enquadra no histórico de guerras travadas nessa região. Em uma outra matéria do The New York Times, também se afirma que o Hamas usaria o conflito com Israel para se retratar como a voz da resistência palestina. 
Um ponto em que a cobertura do The New York Times e Folha divergem diz respeito ao sistema israelense que intercepta foguetes e mísseis de Gaza, chamado de "Iron Dome". Na matéria da Folha, o lead já deixa evidente que "dezenas de foguetes foram interceptados pelo sistema de defesa antimísseis de Israel e grande parte caiu em zonas desabitadas". Já na reportagem do The New York Times, o enfoque é no fato de que o sistema interceptou muitos foguetes de Gaza, porém nem perto da maior parte deles. Ainda sobre pontos divergentes na cobertura da Folha e dos jornais The New York Times e The Washington Post, vale lembrar a omissão da Folha quanto ao posicionamento israelense acerca da morte da mulher grávida e do bebê, enquanto veículos norte-americanos deixam evidente esse discurso e os posicionamentos de ambos os lados. A seguir, analisaremos com mais profundidade as principais características observadas

\subsection{Quem tem voz na cobertura do conflito árabe-israelense}

Quando se trata do conflito árabe-israelense, para além da guerra física travada na região, há a guerra de discursos na cobertura midiática internacional. Os discursos empregados por cada lado no conflito podem ressaltar diferentes aspectos do conflito, como o poder e a vitória ou a destruição causada pelo inimigo. $O$ fato permanece que, seja qual for o teor deste discurso, ele tem um grande impacto na percepção do público internacional acerca do conflito. Isso procede ainda mais ao considerarmos que a cobertura jornalística na região tende a reproduzir informações de agências de notícias e expor o que fontes oficias de cada lado do confronto declaram publicamente.

Nesse sentido, a análise das matérias publicadas pela Folha, Estadão, The New York Times e The Washington Post evidencia que quem tem mais voz nessa cobertura midiática são os que providenciam o "discurso oficial". Do lado israelense, quem tem mais voz é o governo, fontes militares como Jonathan Conricus, um porta-voz do exército israelense, Ronen Manelis, outro porta-voz militar e os serviços de emergência de Israel. Aqui cabe ressaltar que o exército israelense não pode ser referido como exército judaico, tendo em vista que Israel é um país laico e há não judeus que fazem parte do exército. Contudo, observa-se que uma matéria do Estadão se refere às forças armadas de Israel como "exército hebreu".

Já do outro lado do conflito, nem sempre é claro quem é o porta-voz dos palestinos e da causa palestina. Tem-se que as matérias citam, principalmente, "autoridades palestinas", "os palestinos", o Ministério de Saúde de Gaza e o líder do Hamas, Ismail 
Haniyeh - também referido como diretor político do Hamas pelo The New York Times. Nesse sentido, nota-se que o Hamas, que controla a faixa de Gaza, procura se posicionar na mídia internacional como a voz do povo palestino, contudo ele não foi democraticamente estabelecido por esse povo, e há outros grupos rivais do Hamas que disputam pelo controle da região. Logo, quando a matéria diz "os palestinos falaram", pode se assumir que está se referindo ao Hamas, porém isso não fica tão evidente como quando se trata de Israel.

Matérias da Folha e Estadão também utilizam agências de notícias como a Reuters e a Agence France Press, o jornal Haaretz e uma TV pertencente ao grupo Hamas como fontes de informação da matéria. Isso comprova ainda mais a ausência de jornalistas apurando diretamente no local, e a dependência de agências e outros veículos para obterem informações. Nota-se, ainda, a presença de fontes internacionais como a União Europeia, o Secretário-Geral da ONU e líderes como Donald Trump nas reportagens, colocando seus posicionamentos com relação ao conflito em Gaza, o que demonstra a repercussão internacional do confronto.

Diferentemente do que se observou nas matérias da Folha, nota-se que há presença de personagens na cobertura do Estadão, o que torna o conflito mais humanizado, e foge da cobertura homogênea dependente de agências de notícias e de discursos de fontes oficiais. Em uma matéria publicada no veículo no dia 5 de maio, ressalta-se o discurso de fontes como a israelense Dikla Diane, cujo ex-sogro foi a primeira vítima da "chuva de foguetes" disparados, de acordo com a matéria, por militantes islamistas. Dikla afirma que atacar seria a melhor solução para o conflito, e é interessante para o público leitor entender como o contexto em que ela se insere pode ter influenciado essa posição política dela com relação ao confronto. Para mostrar o outro lado do conflito e destacar a destruição em Gaza, a reportagem também mostra os questionamentos de Mahmoud Akel, que morava com 11 pessoas em uma casa no campo de refugiados de Nuseirat, casa esta que foi destruída. Mahmoud questiona a culpa dos filhos dele de estarem desabrigados.

Na cobertura do The New York Times e do The Washington Post, ressalta-se a presença de especialistas que colocam suas opiniões com relação ao conflito dentro de um contexto histórico e político mais geral. Há, também, a presença de personagens de ambos lados do confronto, e de líderes internacionais com seus posicionamentos perante o conflito. Nota-se também a presença de declarações de líderes políticos israelenses, dentro e fora do partido do Primeiro-Ministro de Israel, 
como Benny Gantz e Gidon Saar, que contestam decisões tomadas pelo governo israelense. Já no lado palestino, neste caso específico, nota-se um alinhamento, por assim dizer, no posicionamento de Hamas e Jihad Islâmica, que disputam o controle de Gaza, porém cada grupo com seu respectivo porta-voz na mídia. Em uma matéria do The Washington Post, há, inclusive, uma declaração realizada em conjunto pelos dois grupos para enfatizar a necessidade de resistência armada palestina.

\subsection{As imagens da cobertura midiática}

Em uma análise de cobertura jornalística, além de observar o recorte e contextualização dos fatos, a escolha de palavras na construção do texto e da manchete, dentre outros fatores, é imprescindível, também, analisar as imagens utilizadas para ilustrar essa cobertura. Nesse sentido, deve-se analisar a fonte dessas imagens e que história elas pretendem contar, de modo a acrescentar informações ao texto da notícia.

No que se refere a fonte dessas imagens e fotografias utilizadas nas reportagens dos jornais estudados, tem-se que, em sua grande parte, são provenientes de agências de notícias internacionais. Dentre essas agências, destacam-se Agence FrancePresse, Reuters, Xinhua e Associated Press. Cabe aqui ressaltar que muitas matérias online utilizaram, além das fotografias, outros recursos de diferentes mídias na cobertura jornalística - como vídeos, mapas e podcast. Contudo, para os fins dessa pesquisa, foram levados em consideração somente as fotos que ilustraram as matérias analisadas.

Vale ressaltar que este conflito suscita um alto nível de apelo emocional e essas reportagens fomentam o debate público acerca desse assunto. Desse modo, as imagens têm uma função importante na busca jornalística pela objetividade, na medida em que devem mostrar ambos lados do conflito. Na maior parte das reportagens, observa-se que há um certo equilíbrio nessas imagens, no sentido de mostrar os impactos da guerra em Israel e em Gaza, sem favorecer um lado em detrimento do outro. Por exemplo, em uma matéria da Folha de S. Paulo, publicada dia 4 de maio, a primeira imagem mostra um avião israelense que provocou a explosão e fumaça do outro lado da fronteira de Israel com a faixa de Gaza. Abaixo na matéria é utilizada outra imagem, dessa vez tirada da aldeia de Netiv Haasara, ao sul de Israel, mostrando foguetes disparados da Faixa de Gaza. 
Em uma outra matéria deste jornal, publicada dia 5 de maio, observa-se esse mesmo esforço por um equilíbrio nas fotografias: a primeira imagem mostra um prédio destruído por bombardeio em Gaza, e em seguida uma imagem evidencia um local atingido por foguete palestino na cidade israelense Ashdod. Nessa mesma matéria, há, em seguida, a exposição de uma série de imagens mostrando o lado emocional do conflito de ambos os lados, com fotografias de um palestino chorando em um hospital na faixa de Gaza, e de israelenses se protegendo de foguetes palestinos.

Outro ponto a se ressaltar na cobertura midiática brasileira é que, pelas imagens serem de agências de notícias, a cobertura no geral torna-se homogeneizada, e imagens são repetidas em matérias diferentes - o que torna mais evidente a escassez de recursos e investimentos dos veículos brasileiros nessa editoria internacional, tendo em vista a dependência de imagens e informações das agências de notícias. Já na cobertura realizada pelo The New York Times e The Washington Post, também predominam as imagens de agências de notícias que mostram os impactos do ciclo de violência em ambos os lados.

\subsection{O predomínio das agências de notícias}

Este trabalho tornou evidente o predomínio das agências internacionais de notícias na cobertura brasileira e norte-americana do conflito árabe-israelense. Com relação às imagens utilizadas nos jornais estudados, tem-se que a grande maioria é proveniente de agências como Agence France-Presse, Reuters, Xinhua e Associated Press. No caso dos veículos brasileiros, as informações também se baseiam em textos de agências - na Folha de S. Paulo, por exemplo, as matérias são, em grande parte, traduções dos textos de agências de notícias.

Já quando se trata da cobertura realizada pelo The New York Times e The Washington Post, observa-se um maior investimento na editoria internacional. Isso, porque, apesar das imagens provenientes de agências internacionais de notícias, os textos são originais, com repórteres escrevendo diretamente de Israel e de Gaza - o que certamente impacta na apuração e na forma de descrever os fatos, com o olhar mais próximo do conflito. Desse modo, há uma maior diversidade de fontes, analistas, especialistas e personagens, o que enriquece as reportagens e as torna ainda mais informativas, apesar do teor por vezes analítico, para o público leitor.

Desse modo, o trabalho dos correspondentes internacionais do The New York Times e The Washington Post torna os produtos desses jornais mais autênticos, o que 
confere, aos veículos, mais credibilidade e independência. Não há como substituir o olhar do repórter in loco, que entrevista personagens afetados pelo conflito, por uma tradução dos textos de agências de notícias e exposição dos discursos de ambos os lados - sem a presença de especialistas, analistas e personagens que humanizem a matéria para além do "discurso oficial".

Cabe aqui ressaltar que o papel das agências de notícias é fundamental, e a colaboração entre essas agências e jornais do mundo inteiro faz parte da evolução e globalização dos meios de comunicação. A minha ressalva aqui é que o trabalho jornalístico não deve se limitar ao que é recebido dessas agências. A cobertura midiática, sobretudo sobre um tema tão relevante como o conflito árabe-israelense, precisa ir além dos discursos oficiais que se contradizem e das informações reproduzidas por todos os jornais. A cobertura precisa priorizar a apuração, a contextualização e análise dos fatos, para os jornais serem capazes de se diferenciar da homogeneização da cobertura de assuntos estrangeiros.

\section{Conclusão}

Esse trabalho apresenta como objetivo principal entender a atuação da mídia brasileira na cobertura do conflito árabe-israelense, a partir de uma leitura comparada com os principais veículos norte-americanos e de um recorte temporal em torno do conflito entre Gaza e Israel em maio deste ano. Com base em uma revisão de literatura (BICKERTON, 2018; KLAUSNER, 2018; BRATIC, 2006; BUMLER, 1995; MONTEFIORE, 2011) e na análise das matérias online publicadas pelos jornais Folha de S. Paulo, Estado de S. Paulo, The New York Times e The Washington Post, foi possível chegar a algumas conclusões acerca desse assunto. Contudo, reitero que, por mais que os resultados possam se aplicar, em um sentido mais geral, à cobertura brasileira do conflito árabe-israelense, essa pesquisa tem limitações. Isso, na medida em que apenas estuda alguns veículos específicos em um intervalo de tempo curto. Outros estudos que possivelmente analisassem a cobertura de um número maior de veículos, incluindo jornais israelenses e árabes, e em um intervalo maior de tempo, poderiam chegar a resultados ainda mais conclusivos e abrangentes.

Essa pesquisa ressaltou a atenção midiática voltada ao conflito árabe-israelense, que, por sua vez, gera diversos debates em diferentes esferas internacionais. $O$ posicionamento de líderes do mundo inteiro e de instituições como a ONU em 
matérias sobre qualquer confronto na região, incluindo o que foi estudado nessa pesquisa, torna evidente a importância e a dimensão que o conflito árabe-israelense adquire internacionalmente. Os motivos para esse apelo emocional e interesse público são diversos, mas, dentre eles, as características históricas, religiosas, simbólicas e estratégicas que conferem particularidade ao conflito. Ademais, quando se trata de jornalismo internacional, observa-se que a cobertura de situações de guerras e violência ocupa papel de destaque na mídia, e são essas imagens que captam audiência e prendem o interesse do público.

Por conseguinte, o nível de responsabilidade de um repórter, e de um veículo, que cobre o conflito árabe-israelense é significativo. Isso, tendo em vista que esse trabalho jornalístico é uma das principais fontes de informação, sobre o confronto, para pessoas que estão longe fisicamente da região, e que podem não ter muito conhecimento sobre o histórico do conflito. É primordial, desse modo, colocar todos os fatos em contexto para o leitor, não omitir posicionamentos e dar voz não somente às fontes oficiais, mas também a analistas, especialistas e personagens que humanizem e aproximem o público das questões e complexidades que envolvem o confronto.

Contudo, o que se percebe na cobertura de veículos brasileiros, ainda mais a partir de uma leitura comparada com jornais norte-americanos, é uma homogeneidade limitadora. Por homogeneidade, entende-se uma repetição de imagens, informações e textos de agências de notícias e uma exposição de "discursos oficiais" de cada lado sem conclusões concretas. Na análise, foi possível observar os perigos de apenas expor - ou omitir - esses discursos, sem uma maior apuração e diversidade de fontes. Cabe aqui destacar que, na leitura dessas reportagens, nem sempre é claro quem é o porta-voz do discurso oficial, principalmente quando se trata do lado palestino. Isso, porque há diversas facções que disputam o poder, sem um governo democraticamente estabelecido. Desse modo, quando a matéria diz "os palestinos falaram", em discursos oficiais, não fica evidente ao leitor a quem o repórter se refere. Além disso, ao designar o lado israelense, foi possível observar que religião e política, muitas vezes, se misturam, como em matérias que se referem ao exército israelense como "exército hebreu", apesar de não judeus também integrarem esse exército.

Esses aspectos evidenciam uma falta de apuração e de compreensão sobre os dois lados do conflito, e isso se torna ainda mais complexo visto que, na mídia, é travada 
uma verdadeira guerra de discursos entre cada lado do confronto. Desse modo, os veículos precisam ir além da mera reprodução de imagens e textos de agências de notícias e exposição de declarações de fontes oficiais. É cada vez mais necessário tomar cuidado com o recorte ou possíveis omissões de fatos, e contextualizar essa guerra de discursos que se contradizem. Nesse sentido, a partir de uma maior apuração e análise dos acontecimentos, e com um olhar mais próximo da história e simbolismo do conflito, torna-se possível informar, de fato, o público acerca do confronto na região.

\section{Referências bibliográficas}

BICKERTON, Ian J. e KLAUSNER, Carla L. A History of The Arab-Israeli Conflict. Nova York, Routledge, 2018.

BLONDHEIM, Menahem e SHIFMAN, Limor. What Officials Say, What Media Shows, and What Publics Get. The Communication Review, Gaza, jan./2009.

BRATIC, Vladimir. Media effects during violent conflict: Evaluating media contributions to peace building. Conflict and Communication Online, n.1, Constança, 2006.

BRITTO, Denise Fernandes. O papel do correspondente internacional na editoria exterior. São Paulo: Programa de Pós-Graduação em Comunicação Midiática da Universidade Estadual Paulista Júlio de Mesquita Filho, 2004. BUMLER, Jay e GUREVITCH, Michael. The Crisis of Public Communication. Abington: Routledge, 1995.

ESSER, Frank e PFETSCH, Barbara. Comparing Political Communication:

Theories, Cases and Challenges. Cambridge: Cambridge University Press, 2004. MONTEFIORE, Simon Sebag. Jerusalem: The Biography. Londres: Weidenfeld \& Nicolson, 2011.

\section{SEGEV, Tom. One Palestine, Complete: Jews and Arabs under the British} mandate. Londres: Abacus, 2001.

VIANA, Bruno César Brito e LIMA, Maria Érica de Oliveira (ed.). Além das fronteiras: uma breve reflexão sobre a trajetória do Jornalismo Internacional. Culturas midiáticas, n. 1, João Pessoa, 2013.

WOLFSFELD, Gadi; FROSH, Paul; AWABDY, Maurice T. Covering Death in Conflicts: Coverage of the Second Intifada on Israeli and Palestinian Television. Journal of Peace Research, Jerusalém, SAGE Publications, 2008. 